\title{
Science, poetry, and music for landscapes of the Marche region, Italy: communicating the conservation of natural heritage
}

\author{
Olivia Nesci ${ }^{1}$ and Laura Valentini ${ }^{2}$ \\ ${ }^{1}$ Department of Pure and Applied Sciences, University of Urbino Carlo Bo, Urbino, PU, 61029, Italy \\ ${ }^{2}$ Department of Biomolecular Sciences, University of Urbino Carlo Bo, Urbino, PU, 61029, Italy
}

Correspondence: Laura Valentini (laura.valentini@uniurb.it)

Received: 27 February 2020 - Discussion started: 27 April 2020

Revised: 20 September 2020 - Accepted: 13 October 2020 - Published: 2 December 2020

Abstract. We present a method to educate the public about landscapes that uses artistic works to broaden the audience, entice people to learn about landscapes in a personal and human context, and thus encourage them to preserve the natural heritage. To this end, we use narratives about a place, in plain language, accompanied by visual presentations, original poetry, and ancient music. Several studies encourage the use of art since it can help to synthesize and convey complex scientific information and create a celebratory and positive atmosphere. Evidence suggests that the arts can deeply engage people by focusing on emotions rather than relying only on comprehension, which is often emphasized in science communication. The multidisciplinary approach arouses an emotional and intellectual experience that enables a personal connection to the place. The work is part of a larger multidisciplinary project covering 20 sites in the Marche region (central Italy), which includes scientific information on geological-geomorphological genesis, trekking itineraries, poetry, ancient music, video, and cultural offerings. The project resulted in live multidisciplinary performances, a book, a DVD, and a website. To give a taste of how we work among the many amazing landscapes of the Marche region, we focus here on three sites from the north, the centre, and the south of the region, namely the sea cliff of San Bartolo, the flatiron of Mount Petrano, and the fault of Mount Vettore, chosen as examples for their different processes of genesis and evolution.

In the long run, our goal is to promote a deeper understanding of landscapes by integrating their origin and physical aesthetic with their cultural and artistic heritage. In doing so, we intend to inspire people to have a new perception of geosites, starting from their physical beauty, building on scientific study and cultural history, and arriving at the knowledge of their social importance. So far, our direct experience with the public has been highly encouraging. The participation at our live shows demonstrated a great interest in geological history, a result that is relevant for the development of geotourism. The method demonstrates the potential to develop a strong personal involvement of visitors with the places, stimulating their curiosity to know how and why that place was formed, and, finally, the desire to visit and protect it.

\section{Introduction}

Ordinary people are often turned off by scientific language, which can seem foreign and dry despite its importance. In contrast, the arts have often been used in history to successfully communicate, influence, and educate. Art is, in fact, able to motivate a large audience, and works of art are an important component in several contexts, such as protests or movements promoting important social and environmental issues, and for raising awareness of social and environmental problems linked to scientific contents (Jordan, 2008; Curtis, 2011, 2012). The arts can help synthesize and convey complex scientific information, promote new ways of looking at issues, touch people's emotions, and create a celebratory and positive atmosphere (Curtis et al., 2012). The arts have, nowadays, been rediscovered as an effective medium for conveying science to the public. Evaluating existing approaches may ultimately help to establish ways of achieving more impactful outcomes and to measure the effectiveness of arts-based science communication to raise the awareness of people about complex topics (Lesen et al., 2016). Evidence 
suggests that the arts can deeply engage people by focusing on the affective domain of learning (i.e. engagement, attitude, and emotion) rather than on the cognitive domain (i.e. comprehension and application), which is often emphasized in science education (Friedman, 2013). Some affirm that, by utilizing both domains, arts-based science communication catalyses attention and creativity by encouraging intuitive thinking (Scheffer et al., 2015). Our work, in harmony and agreement with such research, combines scientific communication with the arts (poetry and music), aiming to expose the public to the great richness of information and beauty represented by a landscape. At the same time, it suggests the efficaciousness of a methodology that can attract visitors to learn about and experience such places.

The geological literature linked to geotourism, cultural heritage, and aesthetics has expanded greatly in the last 20 years (Reynard et al., 2007; Coratza and Panizza, 2009; Gordon, 2018; Reynard and Brilha, 2018). Recently, newer ideas have emerged about the physical landscape, not directly linked to geotourism but as a way of transmitting science to the public in order to increase curiosity and passion that could then also drive tourism (Lanza and Negrete, 2007). The definition given by the European Landscape Convention (i.e. that the landscape is part of the Earth's surface, as perceived by local people or visitors, which evolves through time as a result of being acted upon by natural forces and human beings; Council of Europe, 2000) best expresses the meaning of landscape. In fact, the concept of the perception by the human community is held in high regard. But a perception is different to the degree that attention is high or low, and this depends on the emotional state of the beholder and the interest he or she has in that place. Interest arises from the curiosity of knowing how and why that place was formed, which is, in practice, its geological history.

The Marche is an interesting region from many points of view. The region is still unspoilt in its multiple landscape identities. There are wild promontories on the sea and delightful sandy beaches, rugged mountain landscapes and soft green hills, spectacular karst caves, and deep gorges. This wealth is a consequence of the geological history of the Apennines chain, which has produced great contrasts in physical forms in a very limited space. A geologist who observes a landscape does not just grasp its beauty but starts a mental process that refers back to the complex mechanisms that generated and shaped it, only then to perceive its critical issues and environmental fragility. This understanding inevitably produces a personal appreciation and attachment to the place - even a love for it that would not otherwise be born. These places have been, since the dawn of history, sites of very important human settlements, leaving us with several testimonies of great cultural interest. Around these many beautiful landscapes, it is not difficult to find places of incomparable value; there are towns and villages full of charm, important historic communication routes, extraordinary cultural, artistic, and architectural riches, reli- gious places, and popular local traditions. The region has all the requirements necessary to make the natural environment its strong point for driving public interest, namely the high biodiversity based upon microclimatic, floristic, and faunal variety. The Marche region also saw the birth of great personalities (e.g. Raffaello Sanzio, Giacomo Leopardi, Donato Bramante, Gioachino Rossini, Giovanni Battista Pergolesi, and Gaspare Spontini), while many others lived in or have travelled through these lands (e.g. Piero della Francesca and Leonardo da Vinci).

Nevertheless, people commonly think of the scientific approach its language as being too technical or foreign, and therefore, they often instinctively reject it or fail to understand its message. Geoscientists should be encouraged to transmit their technical expertise more effectively to a nontechnical audience. Some forms of communication related to art, such as poetry and music, directly address the emotional sphere and can involve people deeply. Indeed, if an observer remains open to reception, as he/she becomes engaged by the artwork, technical information could be communicated in a more effective way. Therefore, we have combined three different forms of communication - science, music, and poetry - to convey the history and evolution of a landscape, while being aware that this experience has the power to amplify the beauty of a place and the people's desire to preserve it.

\section{Motivation and objectives}

The purpose of this work is to facilitate a new perception of landscape, beginning with its beauty but ultimately arriving at a practical knowledge of its genesis, and of its environmental problems and weaknesses, which have influenced its cultural history.

A place could have the power to attract people only because of its beauty; nevertheless, the understanding of the geological and geomorphological mechanisms that generated it allows people to fully appreciate the fragility of such beauty. Intimate knowledge might promote the desire of the public to protect a landscape by preserving it over time. Through experience comes an awareness, a connection, and even a love for the territory. Our goal is therefore to stimulate the interest of the public about the genetic aspects of the territory since it is from these characteristics that its beauty, its history, and the culture that has developed around the place are derived.

We apply this approach to the Marche region by using original poetry and music that is suitable for that territory. This method is needed for the difficulty shown by people in understanding the geological mechanisms. The reading of the territory, in fact, is not an immediate process. People do not suspect that the shape of the landscape may be the result of a more or less slow evolution of the territory due to the geological factors; ultimately, the geological culture is still lacking. The combination of music and poetry with the nar- 
ration of the territory can lead people to discover what only an expert eye can observe.

\section{The working method}

A few years ago, we created a team of five researchersartists with different skills, called "Terrerare" (which means rare earth elements but also refers to the rare lands of Italy), linked by a common interest in the territory, whose mission is to promote a deeper public awareness of the landscape. To achieve this mission, we combined three types of "language", namely science, music, and poetry. The choice of such languages is due to our sensibility and expertise; the group, in fact, consists of two geologists, a writer/poet, a musician/musicologist, an actor, and a videographer. The team was born in 2014, when the first live event was organized. Then, we presented our idea at national and international scientific conferences (Nesci and Valentini, 2015; Valentini and Nesci, 2016; Nesci et al., 2018). The whole project took place thanks to an important regional announcement dedicated to the development of the Marche region. It started in February 2018 and concluded in February 2020.

When describing a place, we deliberately choose to start from its geological and morphological features. It allows us to easily identify the key concepts of the evolution of the places. We analyse the landscape from a scientific point of view, trying to explain how it evolves and responds to changes in independent variables such as climatic and tectonic conditions. In doing so, we use simple scientific language conceived for lovers of the territory from all ages and all cultural backgrounds. The geologists analyse the processes and the forces that have created and modified the landscape over time. For each location, we indicate an itinerary with some stops, from which it is possible to enjoy particularly significant glimpses or panoramas of the site, and from where we can narrate the characteristics of the landscape. We convey the knowledge that the Earth has systems, sometimes in very delicate equilibrium, that can respond in an unpredictable, complicated, and often disastrous way to the events or changes originating from geological processes such as climate change or human intervention. The system context allows one to perceive the potential fragility in the environment.

In a second step, the concepts are highlighted and translated into the poetic and musical languages. We believe that establishing a personal connection will let people appreciate the landscape further. Art is able, in fact, to activate an emotional involvement, which ultimately takes one back to a deeper understanding of the landscape. The choice of using original poetry is due to contingent reasons but also for enhancing the effectiveness of the message. Concerning the music, it seemed interesting to match the landscape with ancient music, which was realized with the harpsichord, an instrument with an unusual timbre. In other words, we try to translate the same information but following a different, more direct emotional path. This step examines the landscape from a perspective that is more closely related to the visual and emotional impact that a place evokes, namely its history, its cultural significance, and the perception of its fragility in a human context. The latter is perhaps a more abstract path and more intimate, which develops fully through the use of communication forms that exist to express human feelings through artistic language such as music and poetry. According to Ham (2013), the best approach is to narrate the science of landscape in a rigorous but simple way by humanizing and associating it with the interpretation that poets and musicians can provide. The musician, through musical language, tries to reproduce or harmonize with the emotional impact of a site by searching for a piece of ancient music composed for the harpsichord. The chosen pieces of music communicate aspects of the place through the elements that belong to the musical language. The choice of the musical instrument and the historical period is not accidental. The harpsichord has a punchy and gritty tone that clearly expresses the strength of the landscape. Early music, in addition, is aptly suited for representing natural forms whose history began millions of years ago; many late Renaissance or baroque pieces have been composed to describe a specific situation; in fact, many pieces of music have a title. At other times, the musical form (prelude, toccata, passacaglia, rondeau, variation, canon, etc.) is critical for identifying the associations with the place. In parallel, the poet expressly dedicates verses to these places, using powerful metaphors that become a cognitive tool that links nature and thought. Everything that in the realm of geological process that might be shrouded in mystery is unlocked and made available, lovable, and palpable by the poet through a metric balance and studied cadences of heartbeats. Such analogies foster love for a place, even parts unknown, not only in terms of great scientific interest but also for the purely poetic fascination of all the things which emerge from the deepness of time.

The sites of the project were selected for their high inherent aesthetic value and diverse genesis and evolution, which result in very different visual impacts. Finally, for each site, we suggested a section dedicated to one aspect of natural, historical, or cultural interest; this was a proposal to know something more about that place.

How are all these elements communicated to the public?

The results are offered to the public through different products. An important medium is a book (Nesci and Valentini, 2019) dedicated to 20 sites in the Marche region (central Italy). The contents of the book have been summarized and posted on a website (https://www.terreraremarche.it, last access: September 2020). The poems and the pieces of music, which can be enjoyed individually for each place, are also the soundtrack of videos that, by using beautiful images of these places, creatively interpret the science and nature through the art. These videos can be found on the website and on the DVD attached to the volume, where the book is also avail- 
able in an interactive form. However, above all, the results of our project are offered to the public through live events dedicated to the individual places.

\subsection{Live events}

The most effective and engaging communicative method of our work is through live events. Since the beginning of this project, we planned to address the public directly through shows of about 90 min that combine scientific communication (always by means of simple and popular language) with the reading of poems and the performance of musical pieces. The project, as described above, includes 20 sites from the region, but, due to time constraints, the shows are dedicated only to five or six of them, usually those closest to the place where the live event takes place. The events are structured in two parts; the first is carried out by means of verbal communication, with the employment of figures, sketch, and schemes, which tries to communicate the geological genesis and the geomorphological evolution of the places. It is not an academic lesson; instead, the speaker uses a conversational language to involve the public, focusing on the most interesting aspect of the genesis and investigating how the morphology of the landscape has influenced the history and culture of the place. The speaker guides the public and identifies some key words for the place. These key words represent the link between the science, the music, and the poetry. The speaker, at the end of this part, encourages questions from the public. The second part of the events is a "sensu stricto" performance, which means that the actor and the musician are on a different plane with respect to the public, and there is no interaction between the performers and the public until the end of the performance. The lights are softened, and the shows develop. The performances are conducted in front of a large screen with projections of images and videos of the places. The result is the total emotional immersion of the public in the place. Up to now, we have organized about 10 live events, all in central Italy, always involving intimate and attractive places with acoustic features suitable to the kind of the music (which is ancient and is played by using the harpsichord). Among these locations, the most suggestive were probably the church of Santa Maria in the charming bay of Portonovo (Ancona), which is one of the most spectacular examples of Romanesque architecture in central Italy; the theatre of the prominent Renaissance fortress of Sassocorvaro (PU); and the Sala del Maniscalco, which is part of the magnificent Ducal Palace of Urbino (PU). We are also planning outdoor events, but they have not yet been realized. Moreover, we hope to organize more events outside of the Marche region, and also from elsewhere in Italy, with the aim of attracting people to a territory that still has a great development potential and is still uncontaminated and rich in nature, culture, and traditions.

\subsection{Experience with the public}

In the events, we always distribute a programme of the show, indicating the localities that we are going to illustrate, the text of the poems, and information about the pieces of music chosen for each site; also, we add our contact information to the programme. Until now, we never performed an evaluation of our method. Our experience, therefore, is based on direct feedback from the public. They always show a genuine interest, asking questions and requesting further information by email. Engagements on social media are also an indicator of a widespread interest in our project, with 27000 views on the whole (see the number of views for each video at https:// www.facebook.com/search/videos/?q=terrerare, last access: September 2020), and our Facebook page has 871 followers. The involvement of the public during the shows was always very high, and the number of participants was also satisfactory, even if it is difficult to quantify these factors because they depend on several variables (e.g. the advertising before the event, the season and the weather, the beauty of the place, and how difficult it is to reach). The capacity of the performance hall is also important, as is the context of the event (if it is, or not, linked to a group of events organized on that day in the place). We underline that the project is now at a crucial point. We have concluded the book in February 2020, and we are still improving the website. This material represents a fundamental phase in the diffusion of the project. The project is still young; it was concluded during the height of Covid-19. This global pandemic was responsible for the lack of opportunities to present and promote the project. The collection of data on the responses of the public will represent a good opportunity to test the effectiveness of the method. In the long run, it would be interesting to understand how effective the methodology is at making people fall in love with places and triggering behaviours in defence of the landscape. A questionnaire for the participants at the shows or the visitors of the places will be published on the website. Now, we have the material to propose and deliver public events and collect the responses of the participants. We have not done performances in educational contexts (schools and museums), but the presence of students of different ages at the shows encourages us to move in this direction also. Our events are addressed to a general public of all ages and cultures, an assorted and wide audience of people interested in the territory, the poetry, or the ancient music. Although the events are not conceived for an audience of scientists, we proposed a cultural event linked to a scientific meeting of geomorphologists, which took place in the Ducal Palace of Urbino (Marche region). The show resulted in large participation and enthusiasm from the scientists.

Perhaps the most satisfying results are from those participants who show interest in the landscape evolution and, consequently, the history of human settlements and culture because they realize that we have described the place across all of its history, from its genesis up to the present. According to 


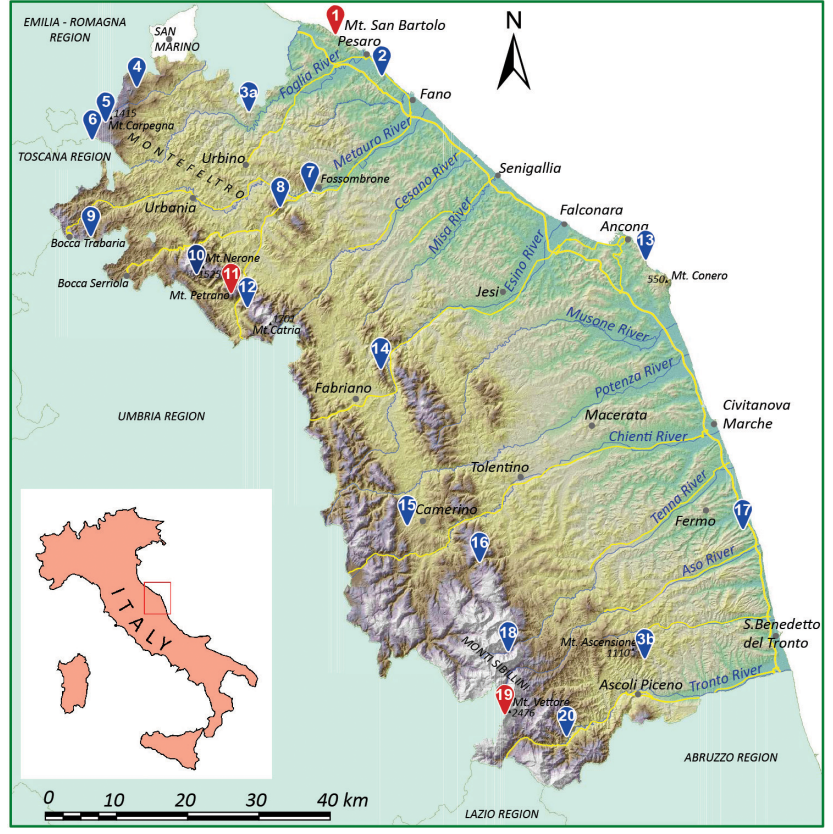

Figure 1. Digital elevation model of the Marche region with the sites involved in the project. The three case studies analysed in this paper are shown in red. (C) 2020 Marche region.

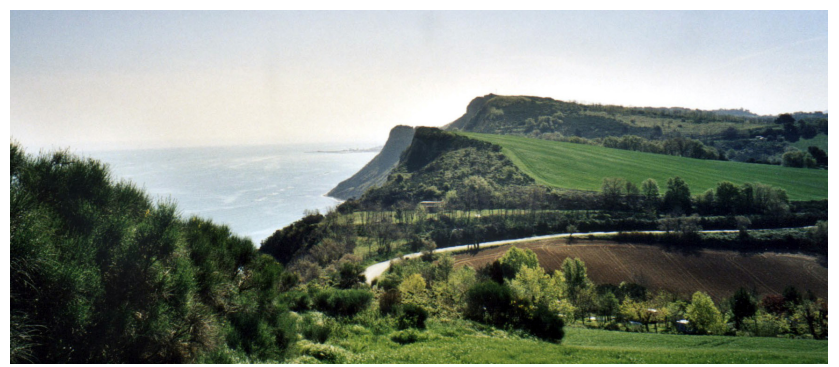

Figure 2. Panoramic view of Mount San Bartolo. The orientation of the cliff is NW-SE. In the background, towards the SE, is the harbour pier of Pesaro.

Strauss (1996), these are the keys to connecting with the listener. We make learning a part of their journey, taking them to a place that they recognize as their own and suggesting that they have a role in the future of the landscape.

Among the many amazing landscapes of Italy, we focus on three case studies from the Marche region (Fig. 1), namely the sea cliff of San Bartolo, the flatiron of Mount Petrano, and the fault of Mount Vettore.

\section{The sea cliff of San Bartolo}

\subsection{The geology}

The northernmost sector of the Marche region is characterized by a high and rocky coast that interrupts the continuity of beaches that fringe the Adriatic Sea south of Trieste.
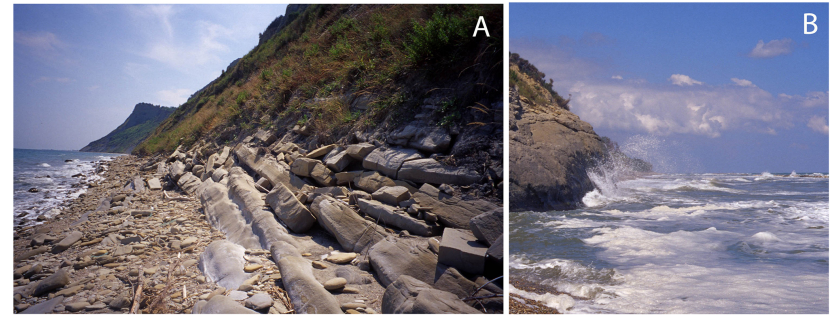

Figure 3. Two stretches of the San Bartolo cliff that show the pebbly beach in the northernmost sector (A) and the substrate eroded by the storm waves in southernmost one (B).

The sea cliff of Mount San Bartolo (Fig. 2) is more than $200 \mathrm{~m}$ high and represents the outermost ridge of the Apennines chain, which extends to the Adriatic Sea. The natural beauty of Mount San Bartolo makes it home to a natural park that is very popular with tourists during the summer season (Savelli et al., 2017). The outcropping of late Miocene rock formations is represented by marls, marly limestones, dark mudstones, and bedded sandstones and marls. The small and sporadic pebbly beaches that protect the base of the cliff and the less protected rocky ridges are both eroded by sea waves during the strongest storms (Fig. 3). For this reason, but also because of the easily erodible lithology and the fracturing of the rocks, the slope facing the sea is affected by extensive landslides that endanger the overlying villages of Gabicce Monte, Casteldimezzo, Fiorenzuola di Focara, Santa Marina, and the entire panoramic road (Fig. 4). The anthropic causes of the instability of the mountain are superimposed on the natural ones; in fact, human activity has intervened heavily and disturbed the natural balance, accelerating erosional processes. One of the most important causes of coastal erosion is the decrease in the sedimentary contribution by the rivers which flow southeast of the relief. The sediment load of these rivers, in fact, contributes to feeding the Pesaro beaches as the coastal currents transport the sediment to the north. The movement of solid matter in rivers has significantly decreased due to the construction of dams on rivers and due to the extraction of aggregates from the riverbeds (Colantoni et al., 2004). To stop the advance of the sea and reduce the risk of landslides, several barriers have been built which, while slowing down the process, have not solved the problem of the erosion of the cliff face, and they corrupt its wild beauty. The response of the coastal system has been the unnatural formation of sandy beaches between the cliffs and the shoreline, due to the triggering of complex refraction and diffraction processes of the wave motion on the breakwater structures, which also causes dangerous coastal currents. The retreat of this stretch of coast has been fast and discontinuous during the Holocene (the last 11000 years), and the shoreline has changed continuously over time. The palaeocoasts are now erased even though there is unmistakable geomorphological evidence of their existence in seaward locations 
of the submerged beach. Geomorphological data testify that, about 6000 years ago, the position of the original palaeocoast, compared to the current one, was advanced by about $2 \mathrm{~km}$, and the relief of San Bartolo was much more extensive and stretched out towards the sea (Nesci, 2003).

Here we propose a geotrail that leads from Fiorenzuola di Focara, an ancient village balanced on the cliff (Fig. 5; stop 1), to the beach below. Along the path, the thick and dense sequence of marly and clayey layers of Mount San Bartolo can be observed, and the precariousness of the rock wall on which the village rests is perceived (Fig. 5; stop 2).

How can we communicate the peculiarities of this landscape through poetry and music? Our main objective was to identify a key interpretation and some key words, which synthesize the main genetic and the process mechanisms, such as stratification, balance, and fragility.

\subsection{The poem}

The title "Up/down/fragile" is related to "handle with care" which is written on the packaging of fragile objects. In a sense, Mount San Bartolo should not exist; the stress placed on it is so much as it undergoes a continuous consumption from erosion, human development, and economic profit. Yet, at the moment, it remains in perfect balance just by virtue of its beauty. The visual (colour), olfactory (scent), and physical (sky and sea) balance is represented by the warmer and motionless hour of the summer season (called the hour without a shadow). For balance, the mountain is the setting of beautiful views and love that history, despite everything, offers. Appreciate this beauty, says the poet, for it is fragile. Below is the poetry in the original language and its translation.

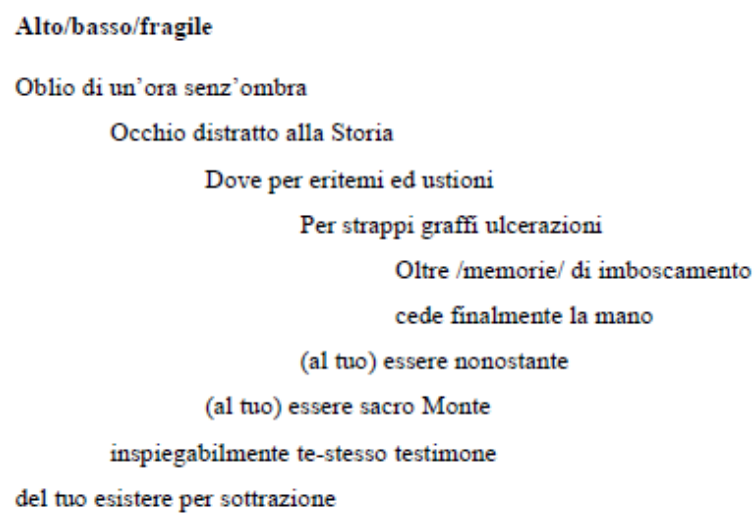

FRAGILE

Dove ogni strategia umana

Mai è apparsa cosi vana

È vanità di utilissimo umano andare
Di avido \& arido e vacanze week end e utilitarie $\dot{E}$ il brusio giallo delle tue ginestre

Impossibili a categorizzare

E poi tu

dispendioso

ancora tu o Monte

orsù (scendi) è ora di andare

sù sù Monte è la tua ora

è una questione tra te $\mathrm{e}$ il mare.

Up/down/fragile

Now is the time:

forget your shadow

steal your eye away from History

sneak through scalds and burns

snatches and drills then overturn

where are your/memories/ ambushing

surrender at last

(to you) being despite

(to you) Holy Mountain

unexplainably yourself

witness of your existence by abstraction

This is you:
FRAGILE

just where each human strategy game

never has been so vain

vain is the valuable man

vain is the eager vain is the barren

vain's out for the weekend on a cheap city car

But there: the never classified

whispering of your brooms

And then you

lavish

you again Mountain

come on (come down) we must try to go right now

hurry up, Mountain, it's time

the matter's between you and the sea somehow

\subsection{The music}

The piece of music selected to represent this site is the "Passacaille" from suite VII in G minor (HWV 432), by George Friedrich Händel (1685-1759). The "Passacaille" is a folk dance of Spanish origin, and it summarizes in its main structure the morphological appearance of the San Bartolo cliff and, in addition, the poetic interpretation by the writer of the poem. The "Passacaille" is, indeed, made up of variations on a ground bass; the same sequence is proposed in a varied rep- 


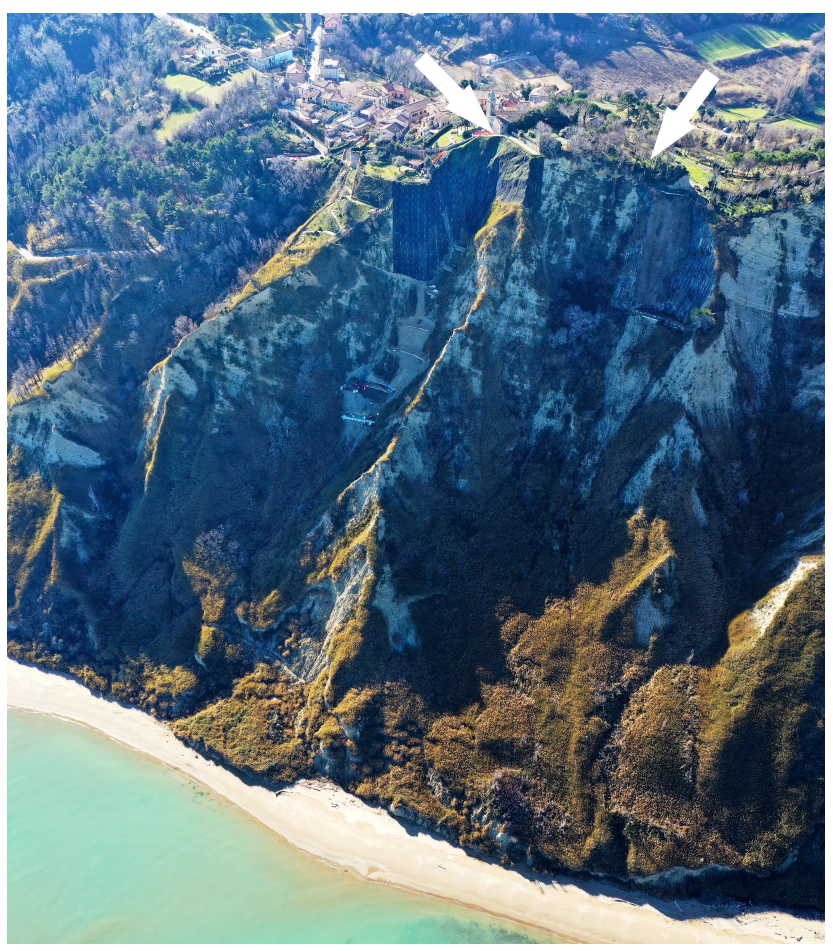

Figure 4. Panoramic view of the active cliffs of Mount San Bartolo. The cliff is oriented from NW (on the right) to SE (on the left). The small village of Fiorenzuola di Focara (at the top of the cliff) is $177 \mathrm{~m}$ above sea level. The arrows indicate the landslide scarps.

etition, following accurate rules of composition. That is exactly like the repetition of the layers on the cliff: layers that are in balance, although at times surprisingly unstable. This piece of music is bright and overwhelming, just as the San Bartolo cliffs are an explosion of colours and vitality. In the last variations, there are several repeated arpeggios like a series of sea waves on the cliff (https://www.terreraremarche.it/ it/db/4357/media/la-falesia-costiera-del-san-bartolo, last access: September 2020).

\section{The flatiron of Mount Petrano}

\subsection{The geology}

Mount Petrano has an elevation of $1162 \mathrm{~m}$, which stands out in the landscape for its characteristic flattened top that visible even from long distances. The gorges of the Burano and Bosso streams, which cross the mountain ridge transversely (Fig. 6), separate Mount Petrano from Mount Catria to the south and Mount Nerone to the north. The panorama that can be enjoyed from Mount Petrano embraces a large territory that offers spectacular views of the major peaks around it and across the whole province of Pesaro and Urbino, up to the Republic of San Marino and the Adriatic Sea. The relief constitutes a beautiful example of an anticlinal ridge (Nesci et al., 2005). Anticlines are one type of folded rock

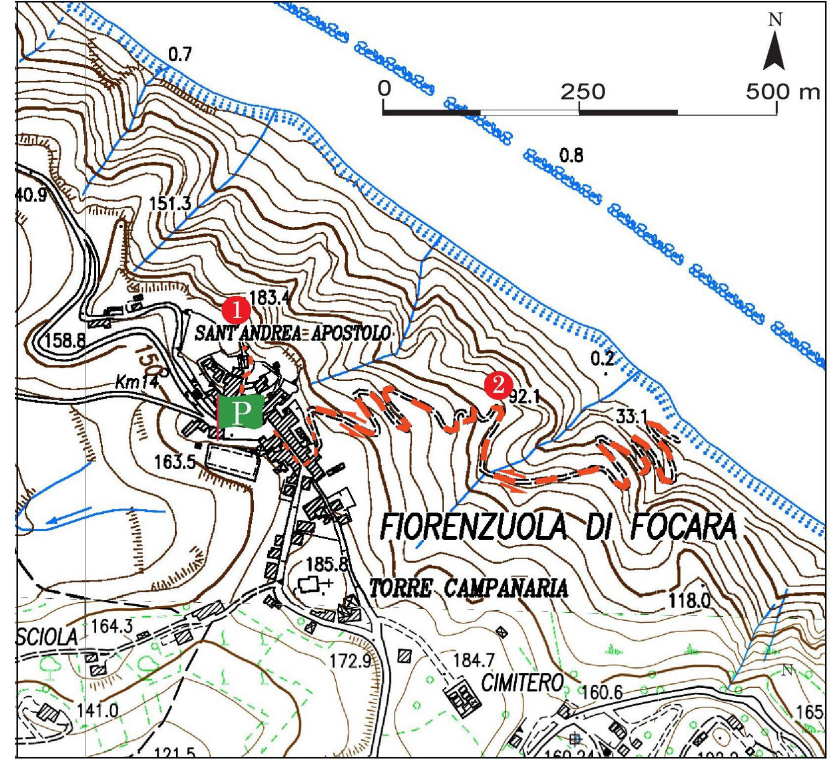

Figure 5. The proposed itinerary, starting from Fiorenzuola di Focara and moving to the beach below. Note: $\mathrm{P}$ - parking area; 1 and 2 - stop. (C) 2020 Marche region.

layer formed by compressive forces that act slowly over a very long time period. But folded rocks are intriguing, hard to imagine, and yet there they are, in plain sight. The morphology of Mount Petrano perfectly follows the wide anticline, and no tectonic dislocation seems to disturb the simple regularity of the fold (Fig. 7), exposing the anticline in its full and awesome natural wonder. Then, too, the sedimentary rocks that outcrop in the ridge are alternately more or less erodible. The large smooth and almost flat upper surface consists of carbonate rocks of the Maiolica formation, which is highly resistant to degradation. The rocks of the Marne a Fucoidi formation, which rests on the Maiolica formation, are more degradable as they are formed by marl and clay. The rocks above are more resistant and are comprised of Scaglia Bianca and Rossa hard limestones (Alvarez, 2019). The selective erosion caused by run-off waters promotes the formation of the so-called flatirons, which are subtriangular prismatic forms that resemble the tip of an iron, from which their name derives. The observation of these spectacular forms is almost like being inside a natural laboratory where the public can observe folded rock that was formed underground, somehow raised to the surface, and then sculpted by streams on the surface. The scale is overwhelming, the forces involved are immense, and the resulting landscape is a work of art. The streams running down the mountain from the flat top of Mount Petrano follow paths related to the degree of erodibility and fracturing in the rocks, finally producing these characteristic morphologies. The flatirons are very well exposed on the sides of Mount Petrano, even if they represent forms that are quite common to other anticline ridges of the Apennines; 


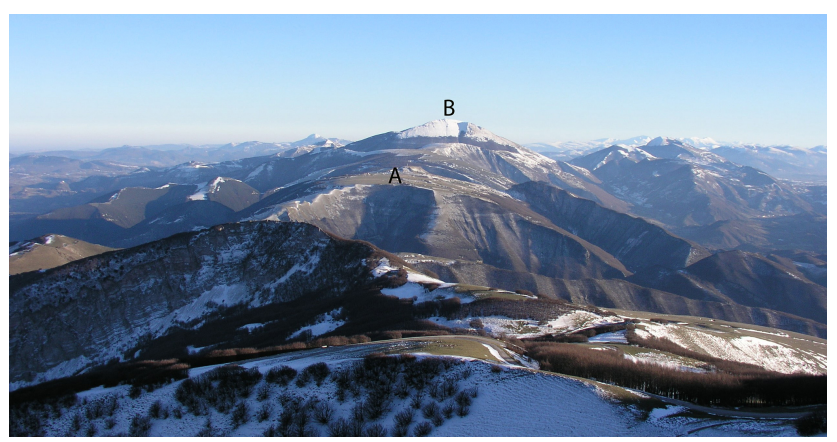

Figure 6. The Catria-Nerone mountains' anticline ridge (oriented NW-SE), with the view from Mount Nerone (NW). Note: A Mount Petrano (1162 m); B - Catria Massif (1701 m).
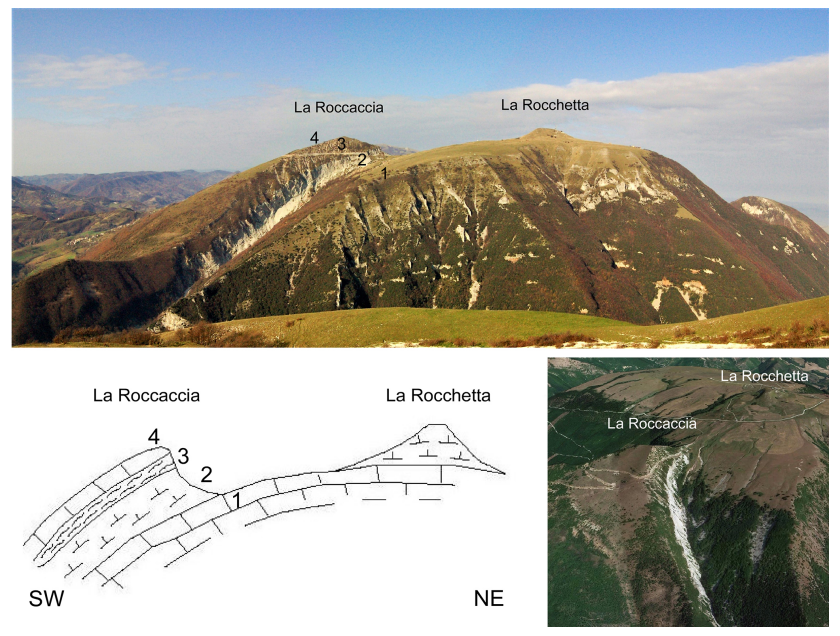

Figure 7. Panoramic view of the Mount Petrano (1162 m) anticline, and an illustrative sketch of the geomorphological features caused by selective erosion. Note: 1 - Maiolica formation; 2 - Marne a Fucoidi formation; 3 - Scaglia Bianca formation; 4 - Scaglia Rossa formation. The image on the bottom right shows an aerial view of La Roccaccia (1065 m) flatiron. (Map data (C) 2018 Google).

the most significant in this area is the one called La Roccaccia (Fig. 8). At this feature is the genetically linked small relief of La Rocchetta $(1163 \mathrm{~m})$, which rises above the structural surface of Mount Petrano (Fig. 7). This little hill represents a remnant of the ancient structure that was removed by erosion.

For this site, we propose a route at the top of the Mount Petrano (Fig. 9). The path surrounds the hill of La Rocchetta and allows visitors to climb to the top of this hill. From there, the visitors can benefit from an impressive $360^{\circ}$ panoramic view over much of the northern Marche region and part of the Umbria Region (stop 1). Finally, reaching stop 2, the visitors can observe, in all its magnificence, the La Roccaccia flatiron.

Again, we pose the same question of how to communicate the characteristics of this place through art. Here, the

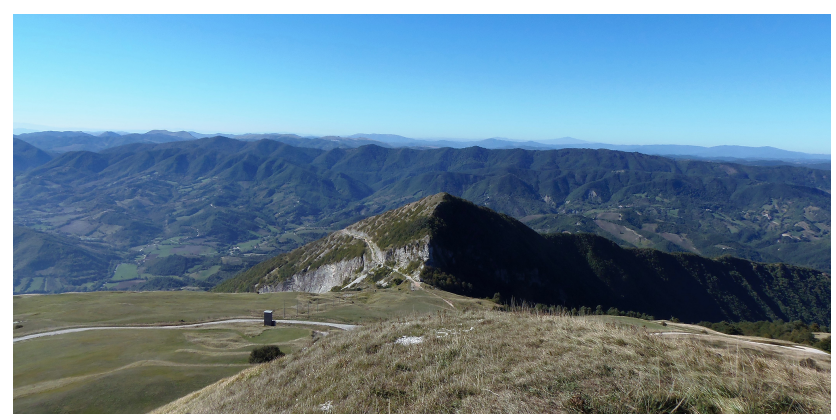

Figure 8. La Roccaccia flatiron (1065 m); view from La Rocchetta.

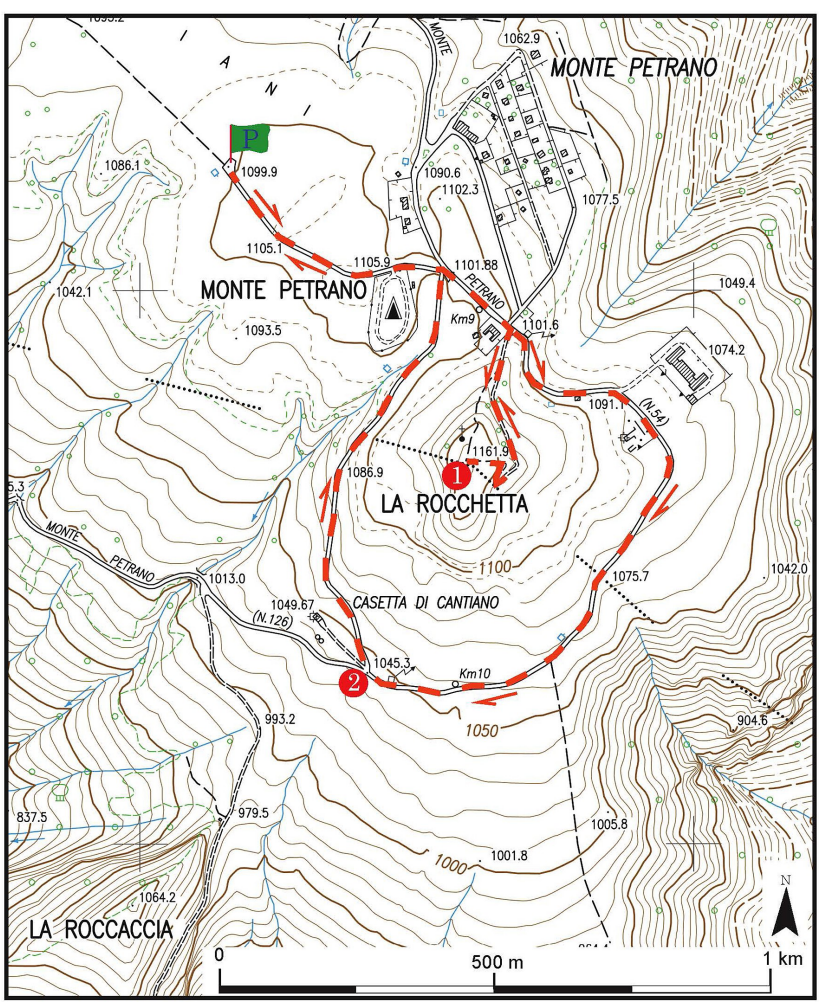

Figure 9. The proposed itinerary at the top of Mount Petrano. Note: $\mathrm{P}$ - parking area; 1 and 2 - stop. (C) 2020 Marche region.

interpretation key words chosen to communicate the place through poetry and music were selective erosion, geometric shapes, and childhood games.

\subsection{The poem}

The vision of pointed shapes on a plain dotted with lawns and flowers conjures holidays and the cries of children who are playing and drawing. On joyful suspension of their play, the reality, far away and out of their line of sight, burns and disappears into the flames. 


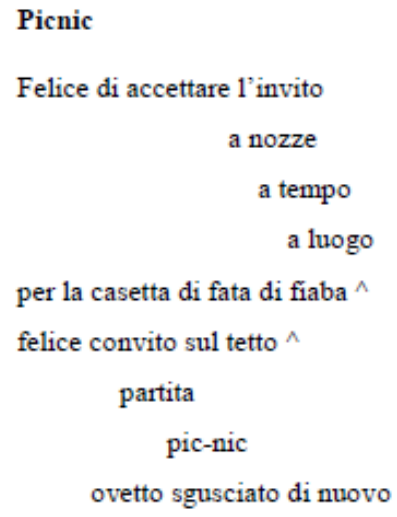

«Mentre dall'alto possiamo ammirare

il moderno complesso andare in fumow

\section{Picnic}

I revel in coming here

$$
\begin{aligned}
& \text { on time } \\
& \text { on place }
\end{aligned}
$$

a fairy tale hut ${ }^{\wedge}$

the merriest banquet up on the roof ${ }^{\wedge}$

scrimmage

picnic

wriggling by this little lovely egg

"While down there we can admire

the modern complex caught by fire"

\subsection{The music}

The music selected was 12 variations in $\mathrm{C}$ major on the theme "Ah! vous dirai-je, maman" (KV 265), which is a keyboard composition by Wolfgang Amadeus Mozart (17561791), published in Vienna in 1785 and probably composed when he was around 25 years old (1781 or 1782). This piece consists of 13 sections. The first one is the theme, which is the French folk song of "Ah! vous diraije, maman". This French melody first appeared in 1761 and has been used for many children's songs, such as "Twinkle, Twinkle, Little Star", "Baa, Baa, Black Sheep", and the "Alphabet Song". This traditional piece deeply fascinated Mozart, who used the theme in a playful composition. The following 12 variations (in rhythm, harmony, and texture) are developed in a very simple way and to produce funny transformations that gradually articulate the original melody, like several pieces of a children's game. The simplicity of this paradigmatic example of musical variation effectively reflects the idea of geometric shapes in childish draw-

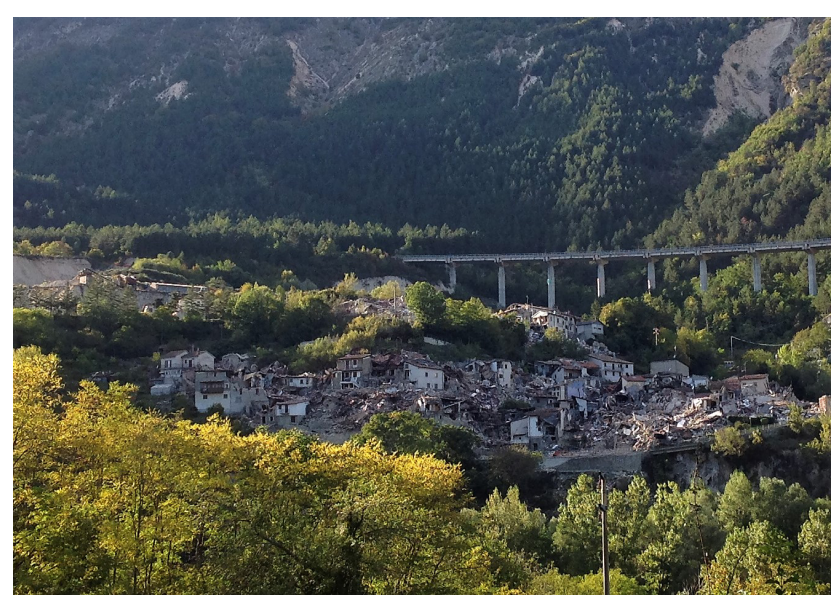

Figure 10. The town of Pescara del Tronto, which was razed by the earthquake of 24 August 2016.

ings or toy building blocks (https://www.terreraremarche.it/ it/db/4359/media/i-flatiron-del-monte-petrano, last access: September 2020).

\section{The fault system of Mount Vettore}

\subsection{The geology}

Central Italy was struck by strong earthquakes in 2016 (Aringoli et al., 2016). On 24 August, a magnitude 6.1 event shook the area between Marche, Lazio, and Umbria, devastating the villages of Accumoli, Amatrice (Rieti), Arquata del Tronto, and Pescara del Tronto (Ascoli Piceno; Fig. 10). A second quake occurred on 26 October, with magnitude 5.9, and the epicentre was between Mount Cardosa, Castelsantangelo sul Nera, Ussita and Visso (Macerata). A total of $4 \mathrm{~d}$ later, on 30 October, an even larger event (magnitude 6.5) destroyed the town of Norcia (Perugia). With the choice of this site, we wanted to instill a beauty shock to infuse positive energy, break the darkness of destruction, and rekindle the life and creativity in a country rich in geological heritage and artistic masterpieces.

The Castelluccio di Norcia basin is a closed depression of over $12 \mathrm{~km}$ in length and $8 \mathrm{~km}$ in width located in the southern part of the Umbria-Marche Apennines and surrounded by an uninterrupted mountain ring. It consists of three closed plains, namely Pian Grande, Pian Piccolo, and Pian Perduto. The Pian Grande (Fig. 11), $5 \mathrm{~km}$ long in the $\mathrm{N}-\mathrm{S}$ direction and $2 \mathrm{~km}$ wide, is the largest and most spectacular one, and it is located to the west of the alignment of Mount VettoreMount Priora.

To comprehend the genesis of this area, it is necessary to understand the formation of the Apennines chain that consists of a compressive thrust system towards the Adriatic Sea. Towards the Tyrrhenian side, in the innermost part of the Apennines compressional system, an extensional zone oc- 


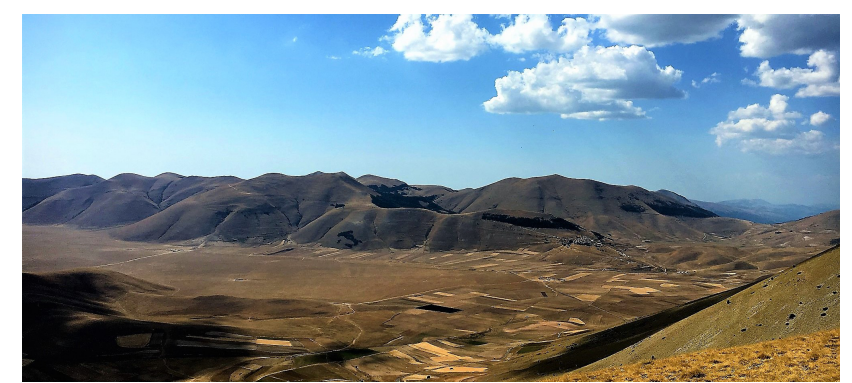

Figure 11. A view of Pian Grande. The plain has N-S direction and mean elevation of $1300 \mathrm{~m}$.

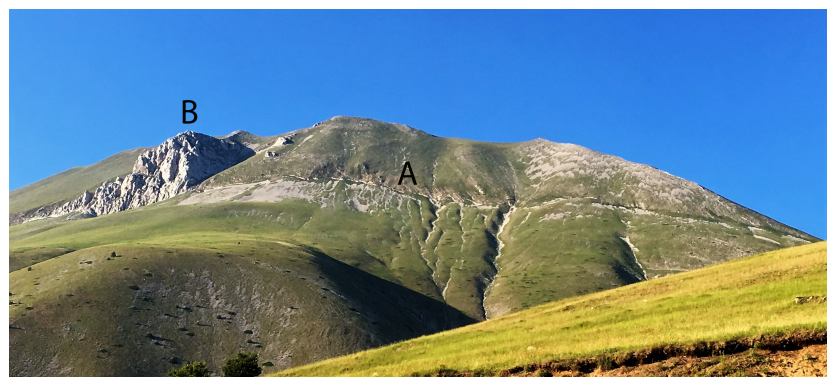

Figure 12. Vettore Massif (2476 m) with a view from south to west, showing the fault (A - Corniola formation) at the base of L'Aquila rock (B - Calcare Massiccio formation).

curs. Just in this sector, large and elongated intermontane plains have formed, which are bordered by complex systems of normal faults and fractures. Imagine a bulldozer that shoves layers of the upper crust, and then, when it stops pushing, some of those layers start to slide backwards. But there was no bulldozer; it is just an Earth system that is evolving whether it is being watched or not. And yet one cannot avoid hearing this evolving process because one can still feel the rumble of this process which we call earthquakes. Our site captures a moment in this process.

The Castelluccio plain was not always a closed depression; in fact, during the Middle Pliocene-Lower Pleistocene ( 3.3-0.7 Ma) the subtropical, humid conditions created a landscape with low-energy relief - a large palaeosurface. The subsequent distensional tectonic phase, characterized by the reactivation of normal fault systems with a NNW-SSE trend and by an intense uplifting of the area, has strongly disrupted the palaeosurface, preserving it only in reduced fragments in the ridges. These processes interrupted and disarticulated the previous landscape, forming a series of tectonic depressions that characterize the whole Apennines area. A bundle of Quaternary faults, in Mount Vettore-Mount Bove to the east and in Mount Castello-Mount Cardoca to the west, surrounds the depression of Castelluccio. This depression is related to an extension direction, oriented from north to south, which led to an oblique movement along the main border faults and to the development of the tectonic depression of Pian Grande (Passeri, 1994).

Starting from the end of the Middle Pleistocene ( $\sim 0.7 \mathrm{Ma})$, the depressions were filled with debris deposited by streams flowing off the adjacent slopes. The debris originated from glacial and periglacial processes, as evidenced from the presence of large cirques and glacio-nival niches in the surrounding areas. The flat surface of the Pian Grande is affected by sinkholes in which the surface waters can infiltrate directly to the subsoil (Aringoli et al., 2018).

To the east of the plain stands Mount Vettore which, with its $2476 \mathrm{~m}$ height, is the major topographic feature of the whole Marche region. Even the most inexperienced eyes cannot miss the large scar that cuts into the mountain (Fig. 12), which is the normal fault that displaces the Mount Sibillini thrust. This fault appears in all its greatness at the base of the Aquila rock, which consists of massive limestone. Other faults are less visible, for example, the huge fault at the base of the mountain associated with the formation of the plain and the many fractures scattered on the side. The whole slope is strongly deformed by landslides, both deep and superficial, and by some fractures that were reactivated by the earthquake.

Mount Vettore represents one of the most popular destinations for excursions in the Marche region. The proposed route (Fig. 13), starting from Forca di Presta $(1550 \mathrm{~m})$ to the crossing of the fault of Mount Vettore, can be, for trained and experienced walkers, only the first part of the longest and most difficult itinerary that leads to the top of Mount Vettore $(2476 \mathrm{~m})$ or to the beautiful lake of Pilato $(1941 \mathrm{~m})$. The route is always well signposted; the difficulty level is medium due to the steepness of the slope and the coarse gravel on which it is not easy to walk. One can enjoy the magnificent view of the Castelluccio plain at stop 1 and then continue towards the top of Mount Vettoretto (2032 m). After about $1 \mathrm{~h}$ of ascent, the fault of Mount Vettore appears, impressive, on the left. The fault plain is clearly visible, exposed for about $2.5 \mathrm{~m}$ (Fig. 14). A little higher up, the route crosses a series of fractures resulting from the 2016 earthquake, some of which form open ground fractures $30-40 \mathrm{~cm}$ wide (Fig. 15).

Here, the interpretative key words chosen to communicate the main characteristics of this place through poetry and music are fault system, readjustment, and balance.

\subsection{The poem}

The spectacle of the suspended mountain in precarious balance captures the attention and forces one to breathe, with one's gaze turned upwards, in an apparently unnatural rhythm. The natural cycle of nature tends to the horizontal world, but some events are opposed, and this creates tension, which can even make one emotional. Reading backwards from the last verse to the title of the poem emphasizes this idea of "return and stay" and accompanies the gaze and the contemplation. 
In your horizontal kingdom

\subsection{The music}

The music selected is Johann Sebastian Bach's (1685-1750) "Canone per Augmentationem in Contrario Motu" (from L'Arte della Fuga; BWV 1080). The basic principle of the canon is imitation. In the canon, a melody is faithfully repeated by the various voices in regular succession. An elementary example, well known to all, is "Fra' Martino campanaro" ("Are you sleeping, Brother John?"), for which the melody is always the same, and it is repeated by other voices at subsequent times. That is the case of a canon in unison, while it is more interesting when the main motif is repeated at different heights to the initial one. The movement of the main voice is "the law", and it is repeated in the other voices, either at different heights or reversed (retrograde canon), mirrored (inverse canon), or with different rhythmic measures (mensuration canon). The absolute pinnacle in the construction of the most complicated of canon compositions belongs to Johann Sebastian Bach. In his masterpieces "L'Offerta musicale" and "L'Arte della fuga", the most interesting examples appear, such as infinite, retrograde, inverse, retrogradeinverse, mensuration, and enigmatic canons. The "Canone per Augmentationem in Contrario Motu" is a perpetual canon with two voices, where the second voice repeats (at the lower fourth) the same melody but is exposed for the opposite motion (specular) with notes of doubled value.

As in the canon's repetition of melody in various voices, in a fault system the movement is followed by readjustment along the various faults in the surrounding area. The analogy between the mechanisms of the canon and this fault system

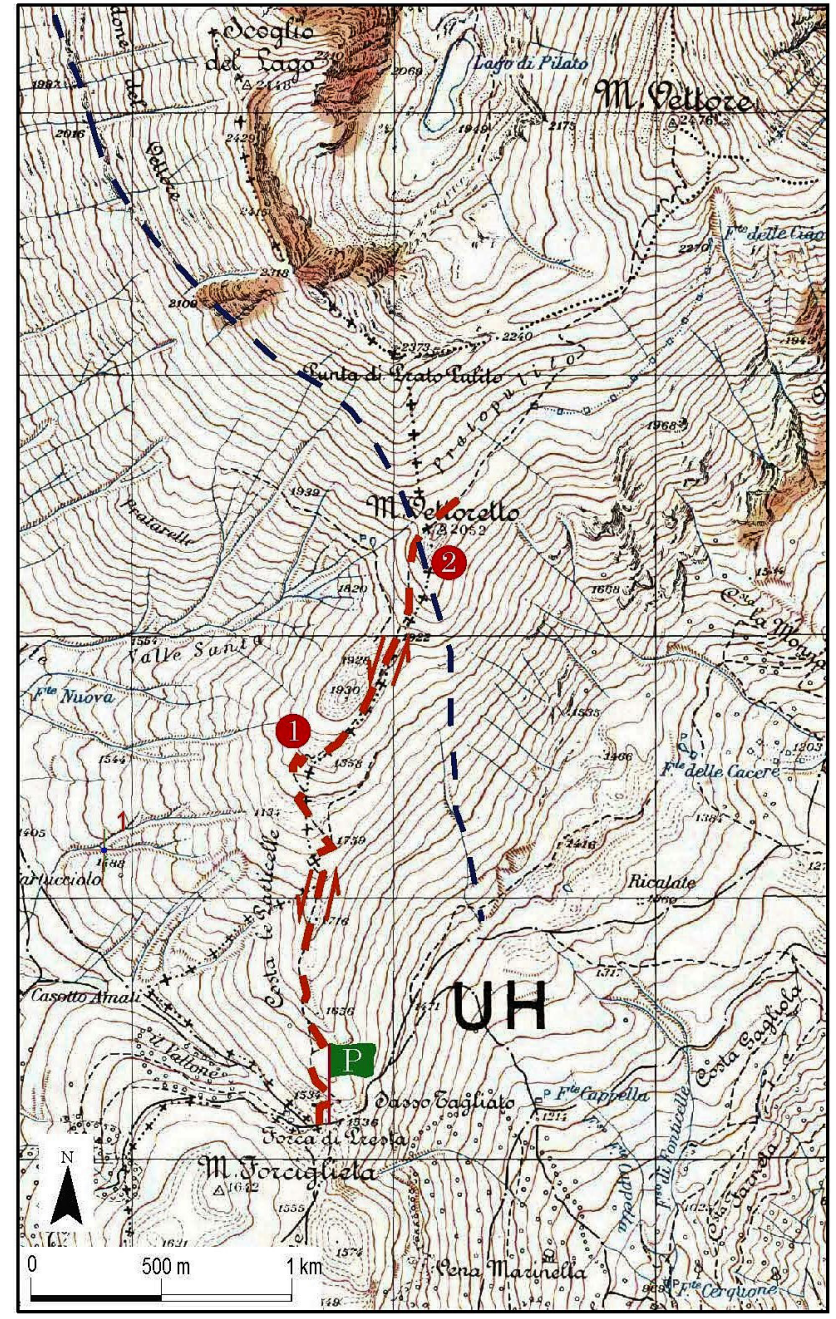

Figure 13. The proposed itinerary for crossing the fault plain on the southwestern side of Mount Vettore. Note: P - parking area; 1 and 2 - stop. Blue dashed line $=$ the fault. (C) 2020 Marche region.

is very strong. It is a wide, intermountain basin, delimited by several faults, mostly distensional, with different orientations but strongly linked together. The fault of Mount Vettore is there, the principal melody, concrete and clearly visible. To its movement, the whole system reacts accordingly, until reaching new equilibrium (https://www.terreraremarche. it/it/db/4374/media/la-faglia-del-monte-vettore, last access: September 2020).

\section{Discussion and conclusions}

This work presents a multidisciplinary and interactive method which seeks to promote the communication of rigorous and complex scientific content, related to the geological genesis and the evolution of a landscape, through art forms such as poetry and music. Art has a great power in and of itself and provides a powerful means for communicat- 


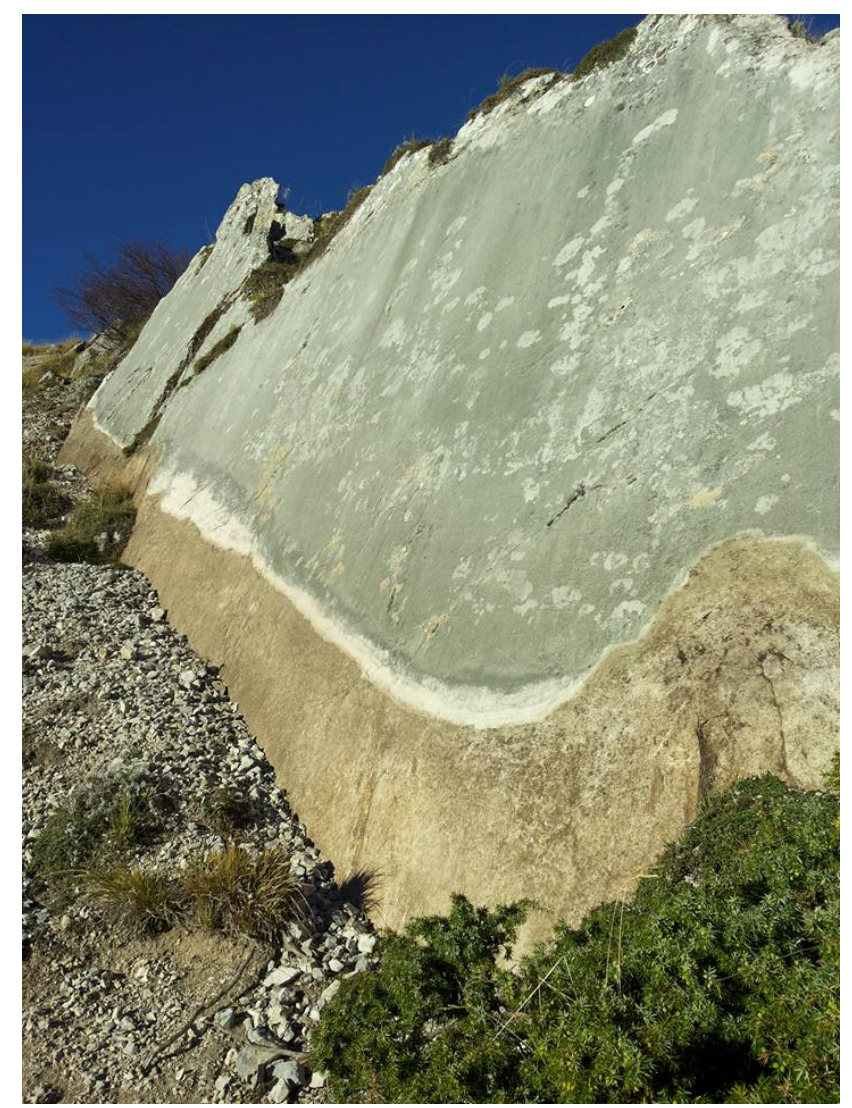

Figure 14. The fault plain (NNW-SSE) exposed for about $2.5 \mathrm{~m}$ and visible on the southwestern side of Mount Vettore.

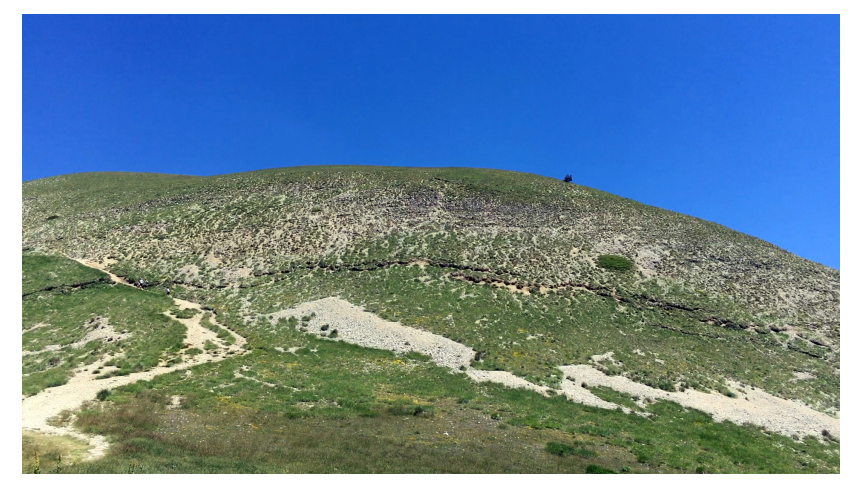

Figure 15. Some fractures (NNW-SSE) related to the 2016 earthquake. They are about $40 \mathrm{~cm}$ wide and located in the debris on the southern side of Mount Vettore.

ing specific subjects, which is an opportunity not to be overlooked. By addressing the emotional sphere, art manages to engage the observer in a profound and passionate way. Based on studies of cognitive and social psychology (Ham, 2013), the communication of information of any nature through the emotional sphere is recognized as being much more effective than traditional communication methods. Our experience confirms this effectiveness. The presence, at our live shows,

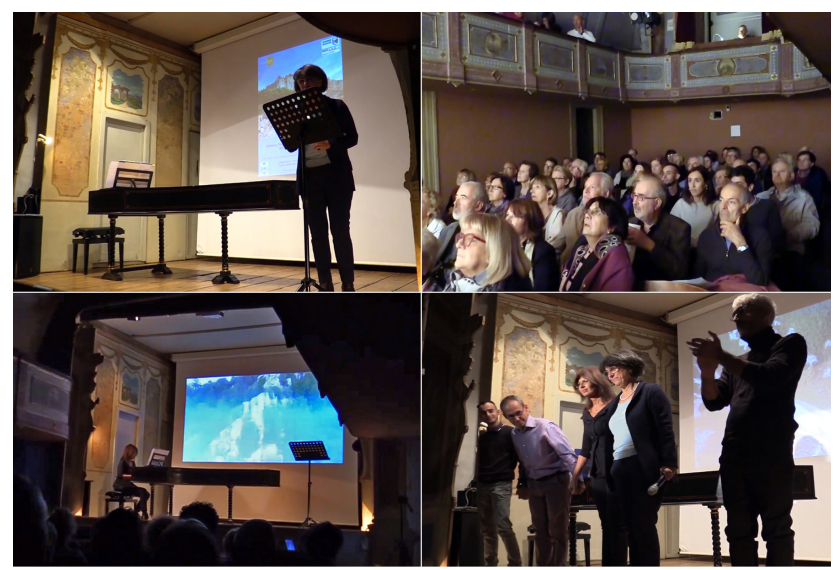

Figure 16. Live show in the theatre of the prominent Renaissance fortress of Sassocorvaro (PU).

of a very large and varied audience, mostly without a scientific background, indicates a great interest in learning about the origins of the landscape. We believe that narrating the landscape through different forms of art creates a personal relationship with the audience in accordance with other studies (Strauss, 1996). The published volume, the DVD with the same contents of the book in an interactive form, and the material posted on the website represent an important milestone of the project. The next step, probably within 1 year, will be to evaluate the efficaciousness of the method.

This work proposes short real or virtual trips to the Marche region: it is possible to go to places, follow paths, and stop there to listen to a piece of music or read or hear poetry. Alternatively, one can follow the route from home, using the virtual mode, by listening to the music and poetry while watching the videos of the places. It is possible to visit the website, where the contents of the book are summarized; one can participate in live shows that are periodically organized in various locations within and outside the Marche region (the site contains information on the dates and places of the shows). The performances are organized following the multidisciplinary communication method described above and combine science, projections of images and videos, recitation of poems, and live musical performances (Fig. 16) with the aim of generating an emotional fusion that introduces the public to the wonders that our country offers in the strongest and most engaging way. The aim of this project is not to provide yet another guide to visiting a beautiful region. The project is in fact much more ambitious since it wishes to stimulate a love for the territory through knowing it in its formative and evolutionary mechanisms. From this knowledge, indeed, it is possible to understand how nature, human settlements, history, culture, and the traditions of a place have developed. This method addresses the curious, the lovers of the territory and art, and those who want to come to know the place and all its aspects. People of all ages and backgrounds can partic- 
ipate in this experience to gain an awareness of the cultural heritage that the landscape represents. The ultimate goal is to increase their desire to understand the fragility of the territory while stimulating, at the same time, the will to protect and preserve it. The landscape must be understood to be loved and protected. We have the scientific responsibility to conserve the priceless landscape heritage of our Earth for future generations.

Data availability. Our underlying research data can be accessed in the web site, and in the number of visualizations of our videos in the YouTube channel (see references).

Author contributions. The authors contributed equally to the research and writing of the paper.

Competing interests. The authors declare that they have no conflict of interest.

Special issue statement. This article is part of the special issue "Five years of Earth sciences and art at the EGU (2015-2019)". It is a result of the EGU General Assembly 2016, Vienna, Austria, 17-22 April 2016.

Acknowledgements. We extend our thanks to Lorenzo Carnevali, the author of the poems, Larry Mayer, for the English language revisions and suggestions, Sauro Teodori, for the graphic support for the maps, and the Marche region, for supporting the project from which this work originates.

Review statement. This paper was edited by Tiziana Lanza and reviewed by Mauro Soldati, Paola Coratza, John Gordon, and Sydney Lancaster.

\section{References}

Alvarez, W.: A review of the Earth history record in the Cretaceous, Paleogene, and Neogene pelagic carbonates of the UmbriaMarche Apennines (Italy): Twenty-five years of the Geological Observatory of Coldigioco, in: 250 Million Years of Earth History in Central Italy: Celebrating 25 Years of the Geological Observatory of Coldigioco, edited by: Koeberl, C. and Bice, D. M., Geol. S. Am. S. 542, 1-58, 2019.

Aringoli, D., Farabollini, P., Giacopetti, M., Materazzi, M., Paggi, S., Pambianchi, G., Pierantoni, P. P., Pistolesi, E., Pitts, A., and Tondi E.: The August 24th 2016 Accumoli earthquake: surface faulting and Deep Seated Gravitational Slope De-formation (DSGSD) in the Monte Vettore area, Ann. Geophys.-Italy, 59, 1-8, https://doi.org/10.4401/ag-7199, 2016.

Aringoli, D., Farabollini, P., Gentili, B., Materazzi, M., Pambianchi, G., Pierantoni, P. P., Bufalini, M., Fuffa, E., Giacopetti, M., and
Pallotta F.: Vivere sulle faglie, Storia dell'Uomo e del Paesaggio. Guida all'escursione, VI conferenza nazionale 2018 anno europeo del patrimonio culturale Appennino, un patrimonio da raccontare, AIGEO, Camerino, 4-6 settembre, 32 pp., 2018 (in Italian).

Colantoni, P., Mencucci, D., and Nesci, O.: Coastal processes and cliff recession between Gabicce and Pesaro (Northern Adriatic Sea): a case history, Geomorphology, 62, 257-268, https://doi.org/10.1016/j.geomorph.2004.03.003, 2004.

Curtis, D. J.: Using the arts to raise awareness and communicate anvironmental information in the extension context, J. Agr. Educ. Ext. 17, 181-194, https://doi.org/10.1080/1389224X.2011.544458, 2011.

Curtis D. J.: Articulating a critical voice: artists who "rattle the cage" about the environment, in: The art of social critique: painting mirrors of social life, edited by: Bingham, S., Rowen \& Littlefield, Lanham, Maryland, USA, 2012.

Curtis D. J., Reid N., and Ballard G.: Communicating Ecology Through Art: What Scientists Think, Ecol. Soc., 17, 3, https://doi.org/10.5751/ES-04670-170203, 2012.

Coratza, P. and Panizza, M.: Geomorphology and cultural heritage, Mem. Descr. Carta Geol. d'It., 87, 189 pp., ISBN: 978-88-2402956-8, 2009.

Council of Europe: European Landscape Convention, CoE Treaty Series 176, October 2000, Strasburg, France, 2000.

Friedman, A. J.: Reflections on communicating science through art, Curator, 56, 3-10, https://doi.org/10.1111/cura.12001, 2013.

Gordon, J. E.: Geoheritage, Geotourism and the Cultural Landscape: Enhancing the Visitor Experience and Promoting Geoconservation, Geosciences, 8, 136, https://doi.org/10.3390/geosciences8040136, 2018.

Jordan, J.: Art, advocacy, and social development: designing and implementing art-based human rights advocacy compaigns at the organization of art for humanity, in: Sustainability: a new frontiers for the arts and cultures, edited by: Kagan, S. and Kirchberg, V., Verlag für Akademische Schriften, Frankfurt, Germany, 230 319 pp., 2008.

Ham, S. H.: Interpretation-Making a difference on purpose, Fulcrum Publishing, Golden, Colorado, ISBN 978-1-5559-1742-5, 320 pp., 2013.

Lanza, T. and Negrete, A.: From myth to earth education and science communication, in: Myth and Geology, edited by: Piccardi, L. and Masse, W. B., Geol. Soc. Spec. Publ., 273, 61-66, https://doi.org/10.1144/GSL.SP.2007.273.01.06, 2007.

Lesen, A. E., Rogan, A., and Blum, M. J.: Science Communication Through Art: Objectives, Challenges, and Outcomes, Trends Ecol. Evol., 31, 657-660, https://doi.org/10.1016/j.tree.2016.06.004, 2016.

Nesci, O.: Evoluzione geomorfologica della falesia costiera del monte San Bartolo (Marche Settentrionali), in: Verso la gestione integrata della costa del Monte San Bartolo: risultati di un progetto pilota. A cura di R. Coccioni. Quaderni del Centro di Geobiologia, Arti Grafiche Stibu, Urbania (PU), 1, 41-53, 2003 (in Italian).

Nesci, O. and Valentini, L.: Three known marchean geomorphosites presented using geomorphology, poetry and ancient music. A new perspective for the development of the area. V Convegno Nazionale AIGeo "Geomorphology for Society: from risk knowledge to landscape heritage", 28-30 September, 2015. 
Nesci, O. and Valentini, L.: TerreRare. Le Marche: Scienza Poesia Musica, Argalia ed., Urbino (PU), ISBN 978-88-89731-20-8, 230 pp., 2019 (in Italian).

Nesci, O., Savelli, D., Diligenti, A., and Marinangeli, D.: Geomorphological sites in the Northern Marche (Italy). Examples from autochthon anticline ridges and from Val Marecchia allochthon, Il Quaternario, Italian Journal of Quaternary Sciences, Spec. Vol., 18, 79-91, 2005.

Nesci, O., Valentini, L., Argalia, S., Baiocchi, S., Brizigotti, M., Carnevali, L., Ceccaroli, C.: Il Paesaggio come risorsa: Scienza Poesia e Musica per la valorizzazione del territorio marchigiano, Convegno "Il patrimonio geologico: una risorsa scientifica, paesaggistica, culturale e turistica" Bologna 7-8 giugno, 2018.

Passeri, L.: Appennino Umbro-Marchigiano, Guide Geologiche Regionali, Società Geologica Italiana, BE-MA, Milano, 301 pp., 1994 (in Italian).

Reynard, E., Fontana, G., Kozlik, L., and Scapozza, C.: A method for assessing "scientific" and "additional values" of geomorphosites, Geogr. Helv., 62, 148-158, https://doi.org/10.5194/gh62-148-2007, 2007.
Reynard, E. and Brilha, J.: Geoheritage: assessment, protection and management, Elsevier, Amsterdam, ISBN: 978-0-12-809531-7, 450 pp., 2018.

Savelli, D., Troiani, F., Cavitolo, P., and Nesci, O.: Rocky Cliffs Joining Velvet Beaches: The Northern Marche Coast, in: Landscapes and Landforms of Italy, World Geomorphological Landscapes, edited by: Soldati, M. and Marchetti, M., CSpringer International Publishing AG 2017, Switzerland, 271280, https://doi.org/10.1007/978-3-319-26194-2_23, 2017.

Scheffer, M., Bascompte, J., Bjordam, T. K., Carpenter, S. R., Clarke, L. B., Folke, C., Marquet, P., Mazzeo, N., Meerhoff, M., Sala, O., and Westley, F. R.: Dual thinking for scientists, Ecol. Soc. 20, 3, https://doi.org/10.5751/ES-07434-200203, 2015.

Strauss, S.: The Passionate Fact: Storytelling in Natural History and Cultural Interpretation, Golden, Colorado, Fulcrum Publishing, ISBN 978-1-5559-1925-2, 1996.

Valentini, L. and Nesci, O.: Landscapes of Central Italy through Science, Poetry and Music. A perspective for educating to the planet sustainability. Geophysical Research Abstracts, 18, EGU20163911, 2016. 